$621.436-762.63: 539.375 .6$

\title{
On the Abnormal Piston Ring Wear of a Marine Diesel Engine*
}

\author{
By Yutaro W.AKuRI**, Tatsuo Yano***, Shoji MrtsutAKE****, \\ and Juji ONO****
}

\begin{abstract}
Abnormal wear of piston rings occurs sometimes with recent marine diesel engines because of severer lubrication condition. The authors studied the mechanism of abnormal wear through analyses of the running-in process of the ring under the lubrication condition at high temperature and low speed, and the preventive measures. It was made clear that (1) the occurrence of abnormal wear was expedited by abrasion with hard abrasive generated by scuffing caused by edge loading of rings at the dead centers of stroke, (2) high alkaline cylinder oil lacked in thermal stability and deposited soft abrasive at above $180^{\circ} \mathrm{C}$, causing scuffing, (3) the character of the compound of metal arising from added elements was dominant as the influence of the cylinder liner material, and total carbon and silicon contents had little effect, (4) chamfered piston rings and finishing of the liner surface by tool cutting were effective in preventing abnormal wear, etc.
\end{abstract}

\section{Introduction}

Recently, operation without overhaul of over 5000 hours is demanded of marine diesel engines and the anti-wear character of the cylinder liner and piston rings has become more important than ever. As for the operating conditions, the residual fuel is commonly used in large engines, and recently a low quality, high sulphur fuel of cracked residue blended with kerosene and gas fuel is used, and B. and C-class heavy oil has come to be used with large trunk piston engines. And to cope with the corrosive wear associated with the use of low grade fuel, the high alkaline cylinder oil (SHD Type) has come to be commonly used since 1957 or 1958 year. Although the high alkaline oil has a high anti-corrosive effect ${ }^{(1)}$, the ill effect of its additive together with the severe lubrication condition accompanying the increased thermal intensity in the cylinder, has given rise to the phenomenon of abnormal wear which posed no problem in the past. Abnormal wear has many aspects from which it cannot be considered to be a mere increase of the rate of normal wear, and it is suspected that it is closely related with the lubrication condition in the

* Received 30 th November, 1962.

** Assistant Professor, Faculty of Engineering, Kyushu University, Fukuoka.

*** Assistant Chief, Laboratory, Mitsubishi Shipbuild ing \& Engineering Co., Ltd.

**** Research Fellow, Laboratory,Mitsubishi Shipbuilding \& Engineering Co., Ltd. running-in stage of the piston ring. Therefore, the authors studied the mechanism of abnormal wear and its preventive measures by the use of a test equipment and a test engine.

\section{Abnormal wear of piston rings and its characteristics}

The rate of wear of piston rings varies with types of engines and conditions of use, and the normal rate with marine engines is less than $1 \mathrm{~mm}$ per 1000 hours. Abnormal wear reaches several mm to over $10 \mathrm{~mm}$, sometimes 20 to $30 \mathrm{~mm}$. Surveys with sea-faring vessels revealed that abnormal wear had the following characteristics.

1) Abnormal wear, if any, occurred always during the running-in stage of shop drive and the maiden voyage, and if it did not occur in that stage, it never occurred at a later stage.

2) Abnormal wear occurred either in all the cylinders or in no cylinder.

3) In the case of normal wear, the initial wear was completed in several to some tens of hours, but once abnormal wear occurred, the normal condition was not reached in hundreds to thousands of hours.

4) As shown in Fig. 1, the rate of wear is normally higher with the upper rings which are under severer lubrication condition of high temperature and back pressure, but the rate of abnormal wear is higher with the lower rings. 
Therefore, with special attention to items (1) and (2) above, the authors compared the shop drive and the maiden voyage conditions between the normal wear vessels and the abnormal wear vessels, and found that the cylinder oil had a conspicuous influence as shown in Table 1 , namely.

5) The use of high alkaline cylinder oil in the shop drive led to a high rate of occurrence of abnormal wear, and the use of high detergent type cylinder oil gave rise to no abnormal wear.

6) The use of high alkaline cylinder oil after the completion of the shop drive posed no problem.

This indicates that the characteristics of cylinder oil has an important meaning and the very initial lubrication condition in the running-in stage is the controlling factor in the occurrence of abnormal wear.

\section{Test equipment and method}

As it was found that the occurrence of abnormal wear was controlled by the lubrication condi-

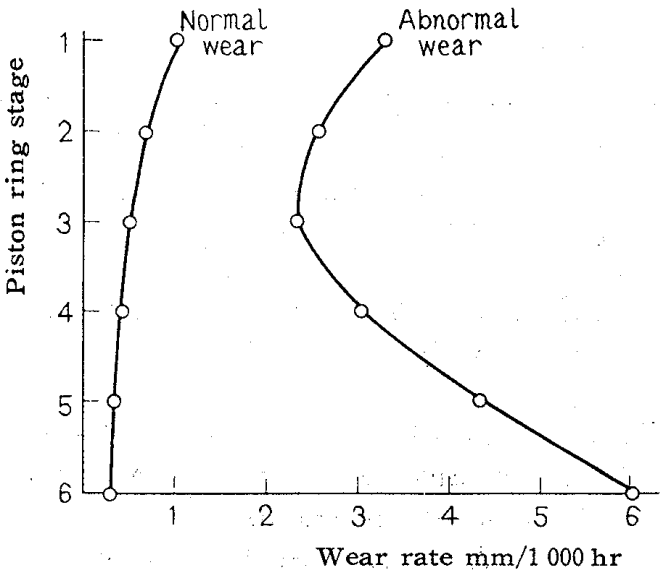

Fig. 1 Example of abnormal wear of piston ring tion in the running-in stage, the authors studied the running-in process with a test equipment measuring the friction of the piston ring. Fig. 2 shows the schematic diagram of the test equipment and Table 2 its specifications. The friction measuring mechanism of this test equipment was reported by Furuhama ${ }^{(2)}$. The test liner is driven by a crank mechanism and the piston is suspended from a beam. The friction exerted on the ring by the vertical movement of the liner is measured with the strain gauge mounted on the beam. The piston has a circumferential groove at the center and the back pressure is applied on the rings with compressed air led in from outside. A small lubricator driven through a cyclo-reducer feeds oil at a very small rate of $0.46 \mathrm{cc}$ per minute. Nichrome wire

Table 1 Type of cylinder oil and abnormal wear

\begin{tabular}{c|c|c|c}
\hline Kind of oil & \multicolumn{2}{|c|}{ Detergent } & $\begin{array}{c}\text { High } \\
\text { alkaline }\end{array}$ \\
\hline \multirow{2}{*}{ Shop drive } & N & 9 & 1 \\
& A & 0 & 8 \\
\hline \multirow{3}{*}{ Maiden-voyage } & N & 2 & 7 \\
& A & 0 & 8 \\
\hline
\end{tabular}

N: Normal wear A: Abnormal wear

Table 2 Specifications of test equipment

\begin{tabular}{l|l}
\hline Cylinder bore & $110 \mathrm{~mm}$ \\
\hline Stroke & $150 \mathrm{~mm}$ \\
\hline Speed range & $120 \sim 1200 \mathrm{rpm}$ \\
\hline Drive motor capacity & $7.5 \mathrm{~kW}$ \\
\hline Lubricator capacity & $0 \sim 0.307 \mathrm{cc} /$ stroke \\
\hline Lubricator driver & EHM -05 Type Cyclo-Reducer \\
\hline Ring sizes & $110 \mathrm{~mm} \phi \times 3 \mathrm{~mm} \times 4.4 \mathrm{~mm}$ \\
\hline
\end{tabular}

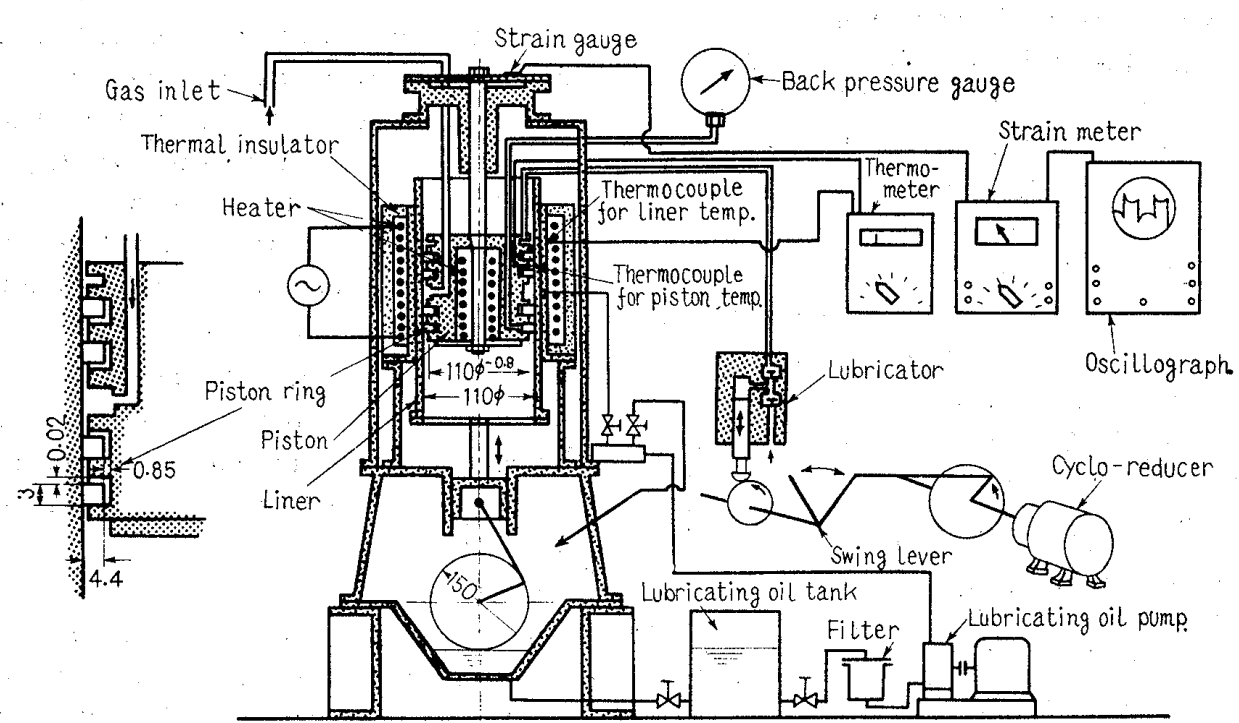

Fig. 2 Schematic diagram of test equipment 
heaters are mounted on the outside of the test liner and on the inside of the piston to raise the temperature of the lubricated section to $250^{\circ} \mathrm{C}$.

Fig. 3 is the picture of the test equipment and Fig. 4 shows the details of the piston. The test liner has the honing finish, and changes of friction with time were measured with new liners and rings.

\section{Analysis of piston ring lubrication condition}

Fig. 5 is an example of cyclic changes of friction on the piston ring at $20 \mathrm{~kg} / \mathrm{mm}^{2}$ of gas pressure, $200^{\circ} \mathrm{C}$ and $120 \mathrm{rpm}$. The following are noticed in Fig. 5.

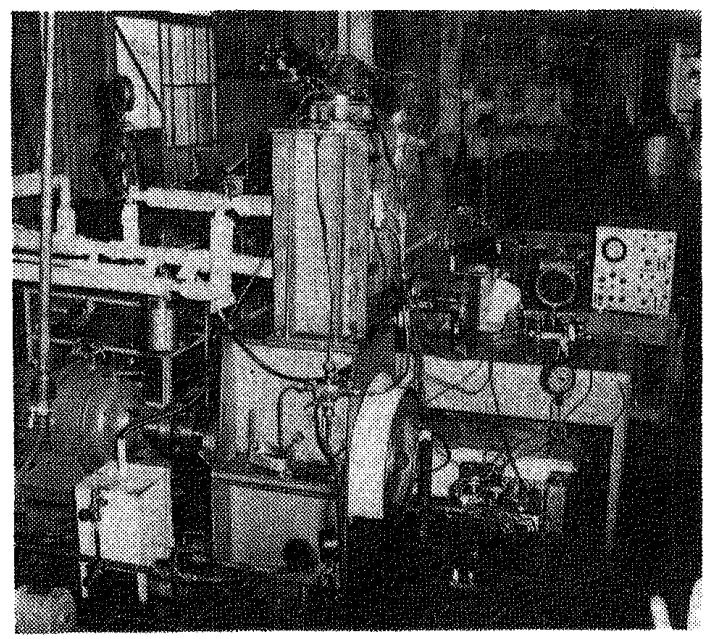

Fig. 3 General view of test equipment

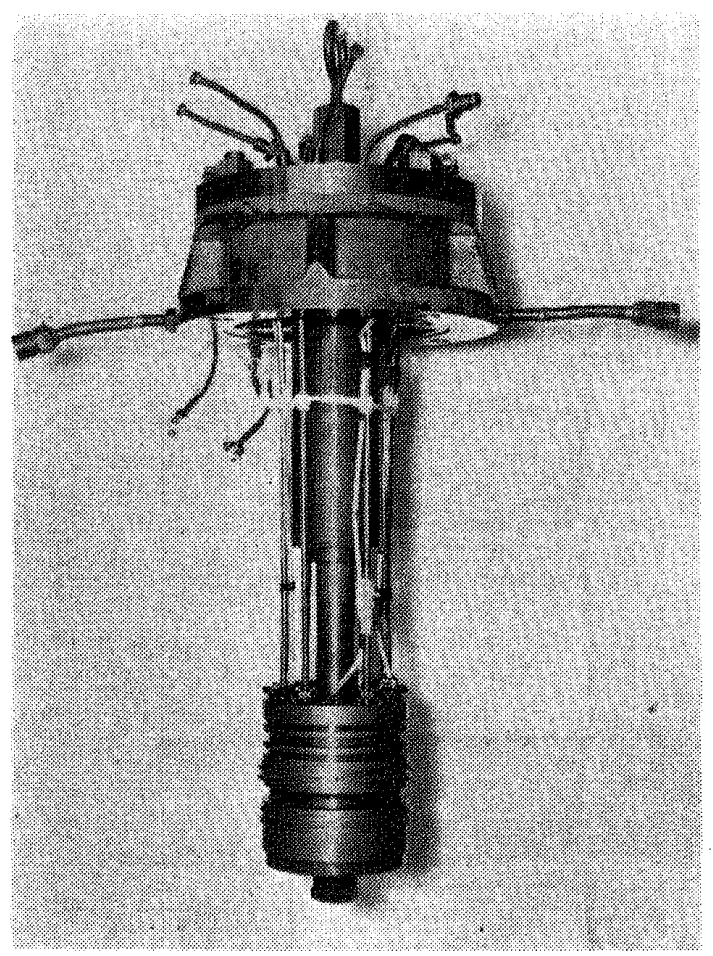

Fig. 4 Details of piston
1) Friction is large at both dead centers of stroke and is small at the middle of stroke.

2) Friction $F_{e}$ when the piston nears the dead center is small, but friction $F_{\max }$ right after the direction of stroke is reversed is very large as compared with friction $F_{m}$ at the middle of stroke.

These facts are representative of the lubrication condition at such high temperature and low speed. When the sliding surface area of a piston ring is $A \mathrm{~cm}^{2}$, gas pressure $P \mathrm{~kg} / \mathrm{cm}^{2}$, ring tension $P_{e} \mathrm{~kg} / \mathrm{cm}^{2}$ and number of rings $n$, the ring load $W \mathrm{~kg}$ is expressed by

$$
W=A P+n A P_{e}
$$

and frictional coefficients by

$$
\eta_{\max }=\frac{F_{\max }}{W}, \quad \eta_{m}=\frac{F_{m}}{W}
$$

Change of frictional coefficients $\left(\eta_{\max }\right.$ and $\eta_{m}$ ) in the initial one hour of new liners and rings were observed as shown in Fig. $7 . \eta_{m}$ is about 0.05 , changing little with time, while $\eta_{\max }$ declines with time.

The lubrication condition is analyzed next on
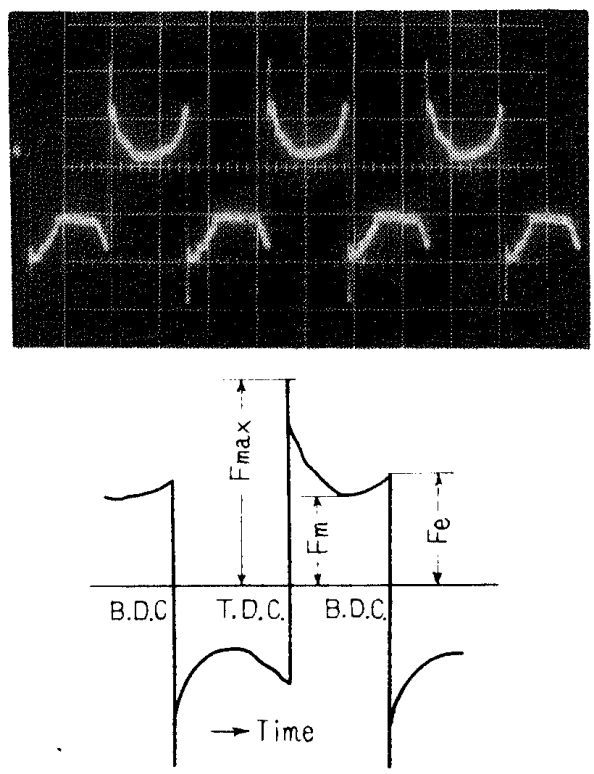

Fig. 5 Example of piston ring friction curve

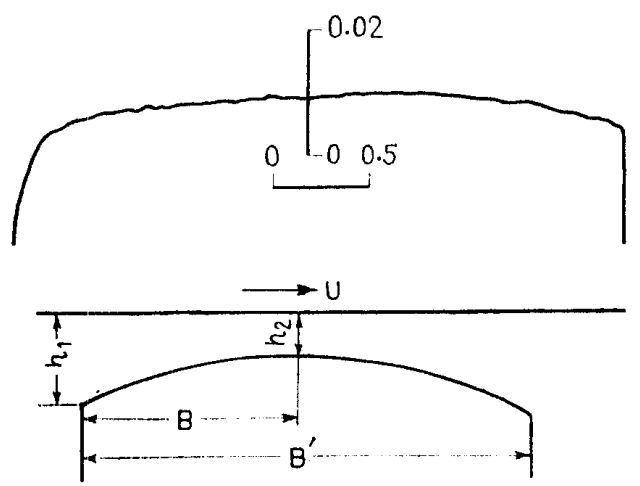

Fig. 6 Profile of sliding surface of piston ring 
the assumption that a quasi-stationary state exists at the middle of stroke. When the frictional coefficient between the ring and the liner is expressed by $\eta$ (aforementioned $\eta_{\max }$ and $\eta_{m}$ ), viscous frictional coefficient by $\eta_{f}$, pure boundary frictional coefficient by $\eta_{b}$, pure solid frictional coefficient by $\eta_{d}$, and boundary frictional coefficient actually measured by $\eta_{b}$ ', the load carrying capacity ratios $x_{f}, x_{b}, x_{d}$ and the resistance ratios $H_{f} / H, H_{b} / H$, $H_{d} / H$ are obtained by Eqs. (3) ${ }^{(3)}$.

$$
\begin{aligned}
& x_{d}=\left(\eta-\eta_{f}\right)\left(\eta_{b}^{\prime}-\eta_{b}\right) /\left(\eta_{b}^{\prime}-\eta_{f}\right)\left(\eta_{d}-\eta_{b}\right) \\
& x_{b}=\left(\eta-\eta_{f}\right)\left(\eta_{d}-\eta_{b}^{\prime}\right) /\left(\eta_{b}{ }^{\prime}-\eta_{f}\right)\left(\eta_{d}-\eta_{b}\right) \\
& x_{f}=\left(\eta_{b}-\eta\right) /\left(\eta_{b}-\eta_{f}\right) \\
& H_{f} / H=x_{f} \eta_{f} / \eta, \quad H_{b} / H=x_{b} \eta_{b} / \eta, \\
& H_{d} / H=x_{d} \eta_{d} / \eta
\end{aligned}
$$

With case cast iron, $\eta_{d}$ is approximately 0.5 , $\eta_{b} 0.06$ to 0.08 and $\eta_{b}{ }^{\prime} 0.2$, and $\eta_{b}$ has to be estimated by calculation. Fig. 6 shows the profile of the sliding surface of a test ring after normal running-in, and it takes a convex shape with the central part about 5 microns high. Consequently, viscous oil film is formed by the wedge action of the sliding ring. The load carrying capacity in such cases was reported by Furuhama ${ }^{(4)}$. When the minimum thickness of oil film at the middle part of the stroke is $h_{2} \mathrm{~cm}$, the viscous frictional coefficient $\eta_{f}$ is approximately given by the following equation:

$$
\eta_{f} \cong U \mu n A / W h_{m}, \quad h_{m}=\left(h_{1}+h_{2}\right) / 2
$$

where $U$ is the sliding velocity of the ring $(\mathrm{cm} / \mathrm{sec})$ and $\mu$ the oil film viscosity $\left(\mathrm{kg} \mathrm{sec} / \mathrm{cm}^{2}\right)$.

Analysis of the lubrication condition at the middle of stroke by Fig. 7 yields the results shown in Table 3.

1) The friction of the ring is entirely that of the boundary or solid contact part.

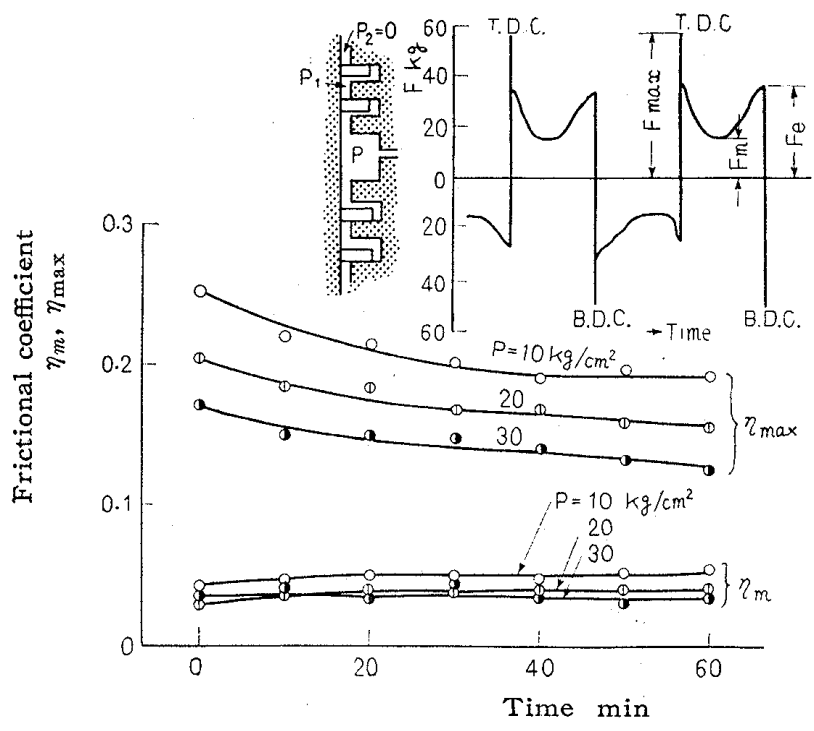

Fig. 7 Changes of frictional coefficient with time
2) The main part of the load is carried by the viscous oil film.

Therefore, lubrication of the ring at the middle of stroke is neither nearly pure viscous lubrication nor nearly pure boundary lubrication, and it takes the frictional characteristics as shown in Fig. 5 .

In the case of pure viscous friction, friction is large at the middle of stroke where the sliding velocity is high and zero at the dead centers, while in the case of pure boundary lubrication, friction is not related with the sliding velocity. The reason why the friction decreases at the middle of stroke is considered to be that the oil film is thick because

\begin{tabular}{|c|c|c|c|c|}
\hline Gas pressure & $\mathrm{kg} / \mathrm{cm}^{2}$ & 10 & 20 & 30 \\
\hline \multicolumn{2}{|c|}{ Measured coeff.of friction } & 0.054 & 0.04 & 0.035 \\
\hline \multicolumn{2}{|c|}{ Coeff. of viscous friction } & 0.0036 & 0.0024 & 0.0018 \\
\hline \multicolumn{2}{|c|}{ Oil film thickness $\times 10^{3} \mathrm{~mm}$} & 1.15 & 0.78 & 0.60 \\
\hline $\begin{array}{c}\text { Load carrying } \\
\text { capacity ratios } \\
\%\end{array}$ & $\begin{array}{l}\text { Viscous } \\
\text { Boundary } \\
\text { Solid }\end{array}$ & $\begin{array}{r}74.4 \\
17.9 \\
7.7\end{array}$ & $\begin{array}{r}81.0 \\
13.3 \\
5.7\end{array}$ & $\begin{array}{r}83.2 \\
11.7 \\
5.1\end{array}$ \\
\hline $\begin{array}{c}\text { Resistance } \\
\text { ratios \% }\end{array}$ & $\begin{array}{l}\text { Viscous } \\
\text { Boundary } \\
\text { Solid }\end{array}$ & $\begin{array}{r}5.0 \\
23.3 \\
71.4\end{array}$ & $\begin{array}{r}4.9 \\
23.3 \\
71.4\end{array}$ & $\begin{array}{r}4.2 \\
23.4 \\
72.3\end{array}$ \\
\hline
\end{tabular}
of the high velocity and the rate of boundary and solid contact, constituting the major part of the frictional resistance, decreases, and the friction

Table 3 Analysis of lubrication conditions of ring

$B^{\prime}=0.3 \mathrm{~cm}, a / B=1, h_{1}-h_{2}=5 \times 10^{-4} \mathrm{~cm}$

$U=95 \mathrm{~cm} / \mathrm{sec}(120 \mathrm{rpm}), \mu=5.1 \times 10^{-8} \mathrm{~kg} \mathrm{sec} / \mathrm{cm}^{2}\left(140^{\circ} \mathrm{C}\right)$
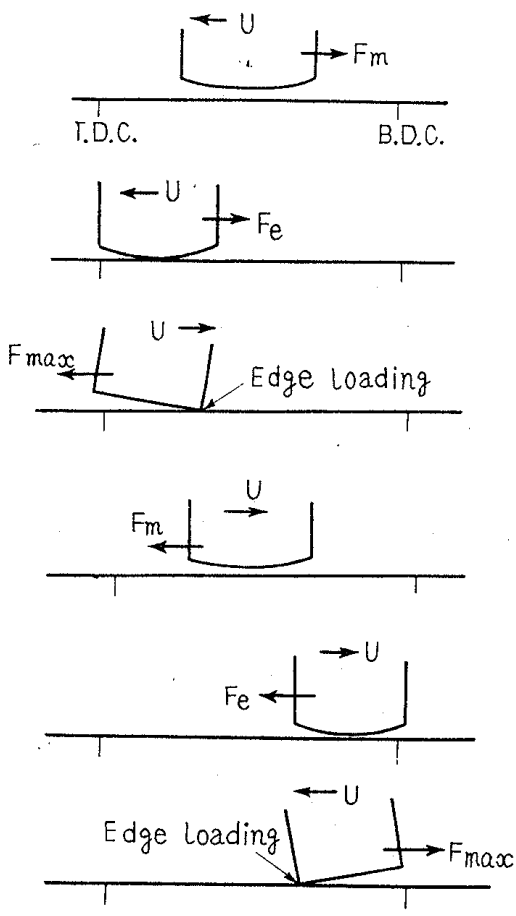

Fig. 8 Initial lubrication conditions of piston ring: 
increases near the dead centers because of decreasing the sliding velocity. Especially, the friction right after the direction of stroke reverses reaches 0.15 to 0.2 in $\eta_{\max }$, indicating that the ring is under a severe lubrication condition where the load is carried by the boundary or solid contact part.

This seems to be due to the edge loading caused by the change in the direction of stroke. In Fig. 7, $\eta_{\max }$ decreasing rapidty with time as compared with $\eta_{m}$ at the middle of stroke remaining nearly constant, means that the edges of the ring are worn down by edge loading and the load comes to be carried by the viscous oil film and the wear comes almost to a stop. Consequently, when the ring has entered the safety zone through the normal running-in, it is no longer very susceptible to later severe lubrication condition, but as it is placed in a substantially severe lubrication condition in the running-in stage due to edge loading, once it is forced, scuffing would result and abnormal wear would ensue.

\section{Influences of cylinder oil}

As stated in Section 2, the rate of occurrence of abnormal wear is high when the high alkaline cylinder oil is used in the running-in stage. There are various explanations for this phenomenon, such as,

1) As the high alkaline oil neutralizes acid, chemical polishing of the liner surface is hampered.

2) Due to low detergency at high temperature, combustion products deposit.

3) High aikaline oil itself lacks in stability and deposits sludge.

The authors compared the high alkaline oil and the high detergent type oil at $160^{\circ} \mathrm{C}$,

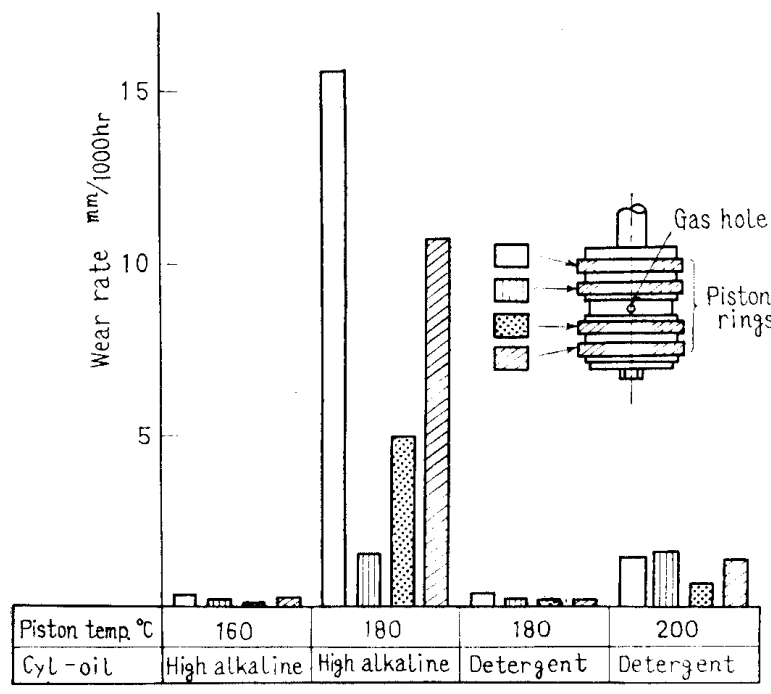

Fig. 9 Wear test results $180^{\circ} \mathrm{C}$ and $200^{\circ} \mathrm{C}$ of the liner temperature on this test equipment. In this case, the above explanations (1) and (2) do not hold because there is no fuel oil involved, and pure comparison of the influences of cylinder oil can be made. The test results are given in Fig. 9. At $160^{\circ} \mathrm{C}$ the ring underwent normal wear both with the high alkaline oil and the high detergent type oil, but at $180^{\circ} \mathrm{C}$ the ring underwent abnormal wear with the high alkaline oil as against normal wear with the high detergent type oil, and at $200^{\circ} \mathrm{C}$ the rate of wear was somewhat higher even with the high detergent type oil. As this test was conducted under a severer lubrication condition than with actual engines, the results obtained are not quantitatively correct, but the following tendency can be observed.

1) The nature of the high alkaline cylinder oil is in itself a factor causing abnormal wear in the running-in stage (independently of fuel oil).

2) Especially, the influence of the temperature of lubricated surface is large.

Fig. 10 shows the conditions of pistons after

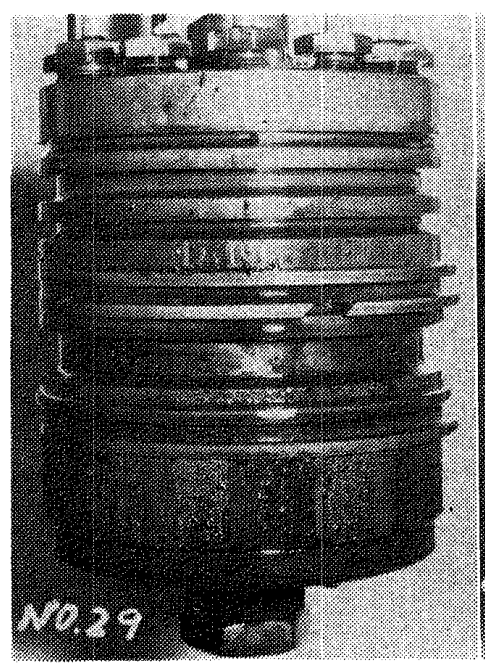

High alkaline cylinder oil used

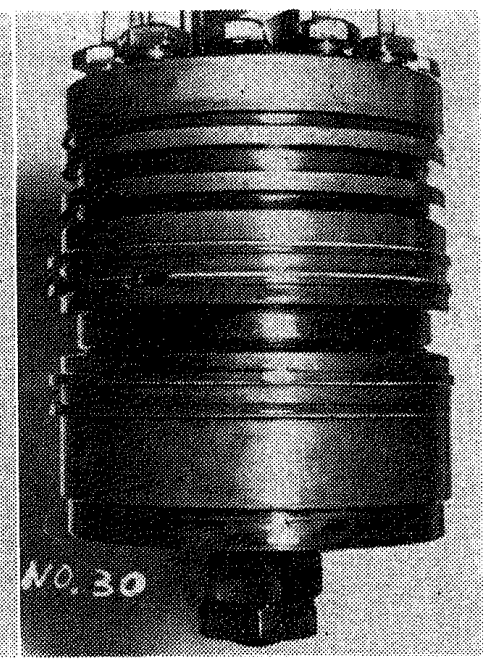

High detergent type cylinder oil used Fig. 10 Appearance of piston after test

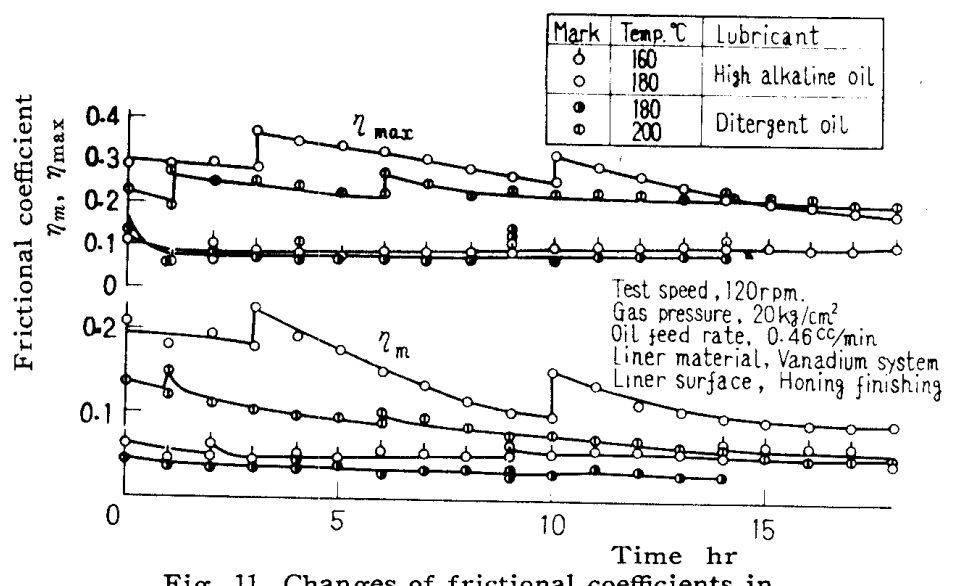

Fig. 11 Changes of frictional coefficients in abnormal and normal wear 
tests at $180^{\circ} \mathrm{C}$. While the piston lubricated with the high detergent type oil is clean, the one with the high alkaline oil has much sludge deposited on the surface. Fig. 11 shows the process of changes of frictional coefficient during the test. While $\eta_{m}$ is about 0.05 and $\eta_{\max } 0.1$ in normal wear conditions both with the high alkaline oil and the high detergent type oil, under abnormal wear conditions $\eta_{m}$ decreases gradually from 0.15 to 0.2 to saturate at about 0.1 and $\eta_{\max }$ from 0.25 to 0.3 to saturate at about 0.2. It is to be noted that as pointed out before, under normal wear conditions $\eta_{\max } \mathrm{de}-$ creases rapidly in the first one hour, but under abnormal wear conditions it does not decrease rapidly and moreover it increases when the engine is stopped and restarted, indicating that the running-in of the ring is not readily completed.

Now to find out which properties of the lubricating oil have larger influences, the authors compared the properties of several kinds of high alkaline oil and high detergent type oil, and obtained the results given in Table 4 . There is not much difference observed with viscosity or viscosity index, but the high alkaline oil has a higher ash content and a higher oil film strength at $100^{\circ} \mathrm{C}$. The extensivity of oil film when $0.01 \mathrm{~m} l$ of test oil was dropped on a hot steel plate was compared as shown in Fig. 12, and it was found that the high alkaline

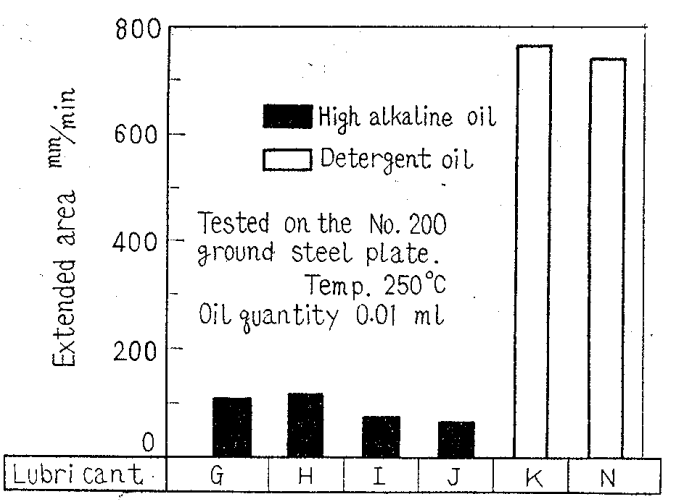

Fig. 12 Oil film extensivity test results oil was far inferior in extensivity to the high detergent type oil. This seems to be due to the fact that the thermal stability is lowered by the amply added alkaline additive (mainly calcium), and sludge is deposited. Table 5 shows the properties of both types of oil. The high alkaline cylinder oil generally lacks in thermal stability and deposits hard sludge at high temperature, which turns into soft abrasive ${ }^{(5)}$ hampering the formation of lubricating oil film on the ring and causing scuffing at both dead centers of stroke where the lubrication condition is severe.

\section{Mechanism of abnormal wear}

As stated before, the abnormal wear seems to be initiated by the breakdown of oil film caused by soft abrasive. In that case, it seems that the rate of wear must be higher with the upper rings subjected to severer lubrication condition with more abrasive deposition, but in actuality once abnormal wear is caused, the rate of wear of the lower rings is higher as shown in Fig. 1. This seems to be explained by the fact that the worn particles (mainly compound of metal) scraped off from the metal surface by the strong surface force of scuffing act as hard abrasive causing secondary acceleration of abrasive wear.

Characteristic of abrasion, the wear is affected by the take-in of abrasive onto the lubricated surface, and the rate of wear is affected by the

Table 5 Characteristics of cylinder oil

\begin{tabular}{l|c|c}
\hline & $\begin{array}{c}\text { High } \\
\text { alkaline oil }\end{array}$ & Detergent oil \\
\hline Alkalinity mg KOH/g & $30 \sim 80$ & $1 \sim 5$ \\
\hline Ash wt \% & $4 \sim 9$ & $0.2 \sim 0.6$ \\
\hline Extensivity of oil film & No good & Good \\
\hline Detergency & No good & Good \\
\hline Thermal stability & Not so good & Good \\
\hline Neutralizivity of acid & Good & No good \\
\hline
\end{tabular}

Table 4 Analysis of test cylinder oil

\begin{tabular}{|c|c|c|c|c|c|c|c|c|c|}
\hline \multirow{2}{*}{\multicolumn{2}{|c|}{ Kind of cylinder oil }} & \multicolumn{4}{|c|}{ High alkaline cylinder oil } & \multicolumn{4}{|c|}{ Detergent type cylinder oil } \\
\hline & & G & $\mathrm{H}$ & I & $\mathrm{J}$ & $\mathrm{K}$ & L & $\mathrm{M}$ & $\mathrm{N}$ \\
\hline Specific-gravity & $15^{\circ} \mathrm{C}$ & 0.935 & 0.932 & 0.911 & 0.939 & 0.909 & 0.920 & 0.908 & - \\
\hline Flash point & ${ }^{\circ} \mathrm{C}$ & 222 & 214 & 224 & 236 & 255 & 242 & 274 & 208 \\
\hline Viscosity (SSU) & $\begin{array}{l}100^{\circ} \mathrm{F} \\
210^{\circ} \mathrm{F}\end{array}$ & $\begin{array}{r}1227 \\
82.5\end{array}$ & $\begin{array}{r}1296 \\
92.0\end{array}$ & $\begin{array}{l}794 \\
77.8\end{array}$ & $\begin{array}{r}1397 \\
\quad 87.0 \\
\end{array}$ & $\begin{array}{r}1287 \\
90.8\end{array}$ & $\begin{array}{r}1472 \\
93.0\end{array}$ & $\begin{array}{r}1076 \\
94.8\end{array}$ & $\begin{array}{l}971 \\
88.0\end{array}$ \\
\hline \multicolumn{2}{|l|}{ Viscosity index } & 57 & 77 & 94.2 & 60 & 75.3 & 65 & 101 & 98 \\
\hline Alkalinity & $\mathrm{mg} \mathrm{KOH} / \mathrm{g}$ & 34.0 & 34.0 & 34.3 & 32.7 & 0.50 & 2.40 & 3.29 & 7.55 \\
\hline Ash & $\%$ & 4.66 & 4.68 & 4.27 & 4.50 & 0.62 & 0.60 & 0.52 & 0.19 \\
\hline \multicolumn{2}{|c|}{ Film strength at $100^{\circ} \mathrm{C} \mathrm{kg} / \mathrm{cm}^{2}$} & 1043 & 1200 & 643 & 850 & 611 & 627 & 627 & - \\
\hline
\end{tabular}


relationship between the size of abrasive and the oil film thickness. And consequently, the rate of wear of the lower rings is higher because of thicker oil film. Fig. 13 shows a profile of the sliding surface of the ring subjected to abnormal wear. Different from the case of normal wear, the ring surface is not rounded but remains flat. In the case of normal running-in, the wear at both edges is expedited by edge loading and the ring surface is rounded off naturally. In the case of abrasive wear, however, the wear at the center part is also expedited and the ring surface remains flat. Thus, once abnormal wear sets in, the formation of lubricating oil film does not progress favourably and abnormal wear would not cease.

\section{Influences of cylinder liner}

As stated in the foregoing, the mechanism of abnormal wear is considered that first the formation of lubricating oil film is hampered by soft abrasive causing partial scuffing, and the hard abrasive scraped off from the surface expedites abrasion secondarily. Consequently, as the influences of liner materials,

1) resistivity to scuffing, and

2) characteristics after scuffing occurred, would come into consideration. The authors, therefore, tested the liner materials of the composition given in Table 6 on a 10PS test engine for the influences on abnormal wear. In the table, Sample A represents the ordinary cast iron of FC system, $\mathrm{B}$ the $\mathrm{P}$ system containing phosphor, $\mathrm{C}$ the $\mathrm{H} \cdot \mathrm{P}$ system with $0.5 \%$ phosphor content, $D$ the $P-V$

Table 6 Composition of test liners

\begin{tabular}{|c|c|c|c|c|c|c|}
\hline Mark & System & $\mathrm{TC}$ & $\mathrm{Si}$ & $\mathbf{P}$ & $\mathrm{V}$ & Note \\
\hline A & $\mathrm{FC}$ & 3.15 & 1.03 & 0.04 & 0 & $\begin{array}{l}\mathrm{P} \rightarrow \text { Low content } \\
\mathrm{V}=0\end{array}$ \\
\hline B & $P$ & 3.06 & 1.05 & 0.34 & 0 & $\mathrm{~V}=0$ \\
\hline $\mathrm{C}$ & $\mathrm{H} \cdot \mathrm{P}$ & 2.77 & 0.97 & 0.50 & 0.04 & $\begin{array}{l}\mathrm{P} \rightarrow \mathrm{High} \text { content } \\
\mathrm{V} \rightarrow \text { Low content }\end{array}$ \\
\hline $\mathrm{D}$ & $\mathrm{P} \cdot \mathrm{V}$ & 3.2 & 1.0 & 0.32 & 0.2 & \\
\hline $\mathrm{E}$ & $\mathrm{P} \cdot \mathrm{V}$ & 3.28 & 0.86 & 0.25 & 0.02 & $\mathrm{~V} \rightarrow$ Low content \\
\hline F & $\mathrm{H} \cdot \mathrm{C}, \mathrm{H} \cdot \mathrm{Si}$ & 3.3 & 1.97 & 0.34 & 0.13 & $\underset{\mathrm{Si}}{\mathrm{TC}}\} \rightarrow \underset{\text { content }}{\text { High }}$ \\
\hline \multicolumn{2}{|c|}{ Test ring } & 3.43 & 2.32 & 0.26 & - & \\
\hline \multicolumn{7}{|c|}{$\Gamma 0.015$} \\
\hline & & 0 & $\mathrm{~L}_{0}$ & 0.5 & & \\
\hline
\end{tabular}

Fig. 13 Profile of sliding surface of piston ring subjected to abnormal wear system and $E$ the $P-V$ system with low vanadium content. Sample F represents the cast iron of $P-V$ system with high total carbon and silicon contents for increased resistivity to scuffing. Fig. 14 is the schematic diagram of the test engine, which has a cylinder of $110 \mathrm{~mm}$ diameter and $150 \mathrm{~mm}$ stroke and the speed of $1000 \mathrm{rpm}$. The test was conducted at 6 PS. Light oil added with carbon disulphide was used as fuel and the high detergent type cylinder oil (marked $\mathrm{K}$ in Table 4) as lubricating oil. The test results are shown in Fig. 15, in which the following are noted.

1) Liner of FC system is advantageous against abnormal wear of the ring, but wear of the liner itself is also large.

2) Liner of $P$ system is advantageous against abnormal wear of the ring and wear of the liner itself is small. The test indicates that the higher the phosphor content within the range of 0 to $0.5 \%$, the better.

3) Liner of $\mathrm{P}-\mathrm{V}$ system is liable to cause abnormal wear of the ring.

4) Sample E, or liner of $P-V$ system with low vanadium content, does not cause abnormal wear of the ring and wear of the liner itself is the smallest.

5) No conspicuous effect against abnormal wear is observed with the high carbon, high silicon system liner.

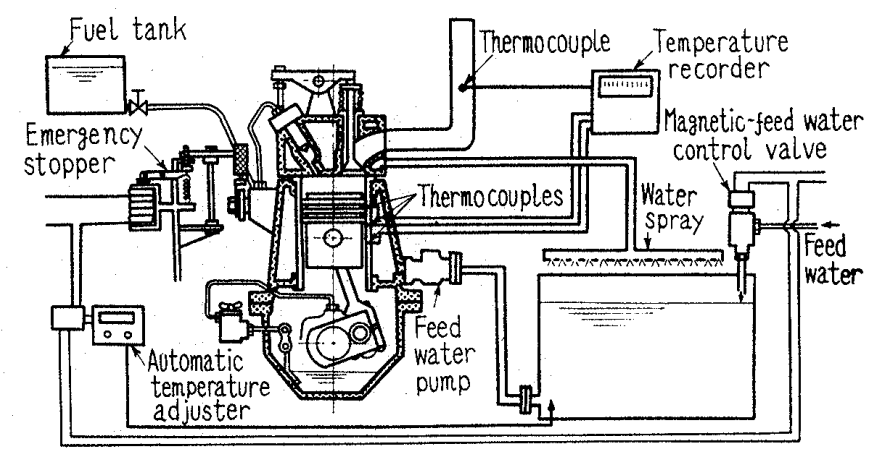

Fig. 14 Schematic diagram of 10 PS test engine

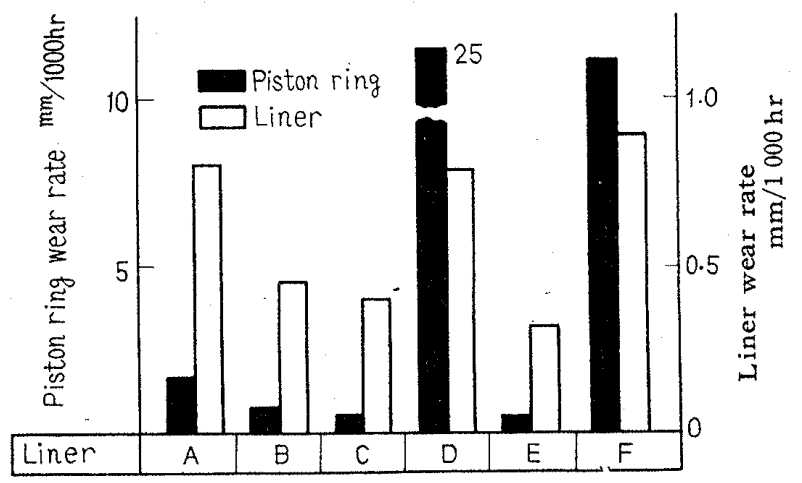

Fig. 15 Wear test results by 10 PS test engine 
It is noted from the above results that abnormal wear of the piston ring is influenced also by the nature of hard compound of metal aiming at the reduction of normal wear of the liner material. Observation of the surface structure of the liner after the test indicates some removal of carbide with the liners of $\mathrm{P}$ and $\mathrm{P}-\mathrm{V}$ systems as compared with the liner of FC system, as shown in Fig. 16. Therefore, in view of the characteristics of abnormal wear described before, it is judged that these hard abrasives $\left(H_{V}=800 \sim 900\right)$ removed expedite abnormal wear secondarily. However, since the liner of $\mathrm{P}$ system does not cause abnormal wear while that of $\mathrm{P}-\mathrm{V}$ system does, it seems that it is the nature of the compound that counts and not the removal characteristic itself. As it is known that carbide $\left(H_{V}=900 \sim 1000\right)$ is crystalized in plate form with the $\mathrm{P}-\mathrm{V}$ system and is effective in normal wear, it seems that the difference of carbide between the $\mathrm{P}$ system and the $\mathrm{P}-\mathrm{V}$ system has a great influence on abnormal wear of the ring.

Now as described before, abnormal wear of piston rings is considered to be initiated by the scuffing due to the breakdown of oil film by edge loading under severe lubrication condition, and in that case the liner material of the high carbon, high silicon system must at least be advantageous. But as stated in (5) above, no marked effect was observed. It is considered that the absolute values of carbon and silicon contents are what influences, but the influence seems to be small within the limitation for marine cylinder liners.

\section{Effect of chamfered piston ring}

The rings undergo strong edge loading and are placed under severe lubrication condition in the initial stage of running-in, and once properly run in, the ring surface is rounded off in arc shape and enters the safety zone, but if laboured in the running-in process, abnormal wear would result. Now it is reasoned that if the sliding surface of the ring is rounded from the beginning and edge loading is prevented, abnormal wear would be prevented. Therefore, the authors made test rings with arc-shaped sliding surface of $1 / 150$ of $H / B^{\prime}$ ratio as shown in Fig. 17, and tested them in combination with the cylinder liner of $\mathrm{P}-\mathrm{V}$ system. The results were quite encouraging and no abnormal wear was observed as shown in Fig. 18. The ratio $H / B^{\prime}$ has the optimum value corresponding to the lubrication condition, which is normally from $1 / 1000$ to $1 / 500$. Fig. 19 is the friction curve after 30 -minute running, and it is noted that $\eta_{\max }$ is

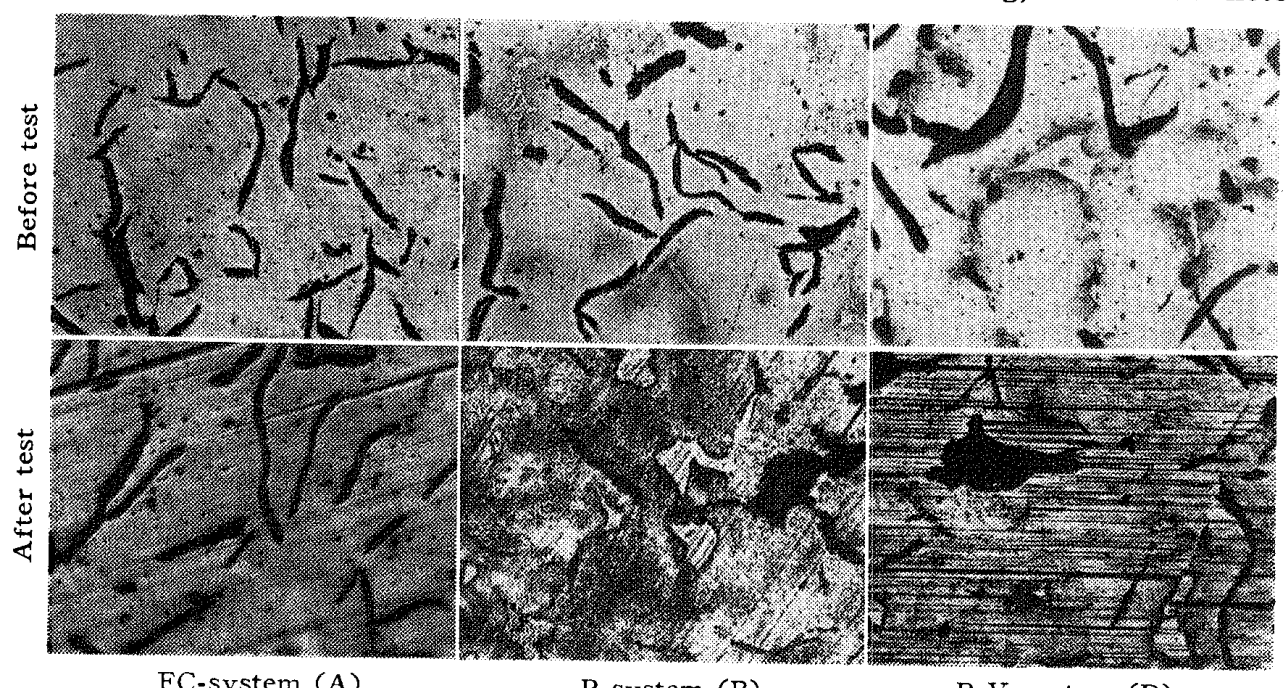

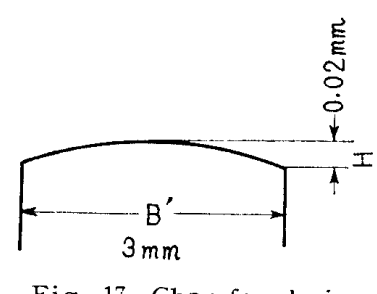

Fig. 17 Chamfered ring (fabricated for test)

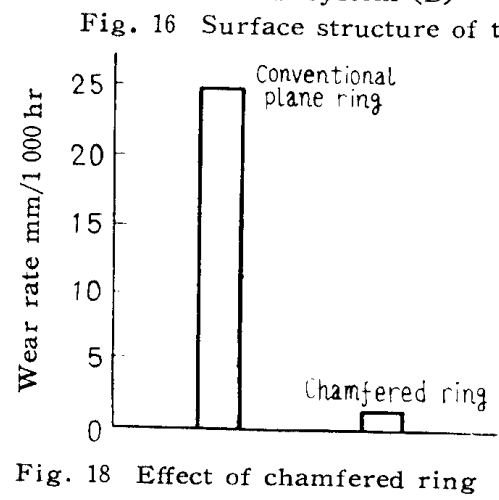

P.V system (D)

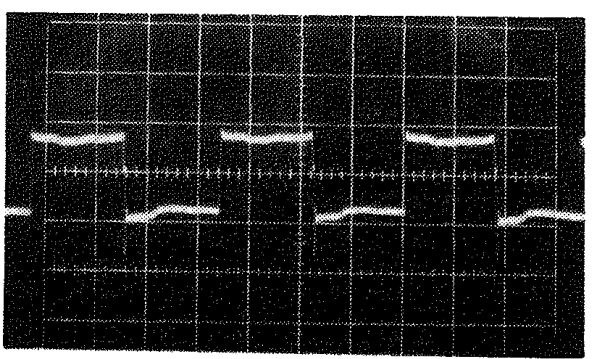

Fig. 19 Friction curve of chamfered ring 
small and edge loading is alleviated. However, $\eta_{m}$ at the middle of stroke is larger than with the conventional ring, and it seems to be due to the excessive $H / B^{\prime}$ value of the test ring.

\section{Influence of finishing of liner by tool cutting}

The test liners in the foregoing test were all finished by honing. To study the influence of finishing by tool cutting, the authors tested the liner materials of $\mathrm{P}-\mathrm{V}$ system with tool marks of $0.5 \mathrm{~mm}$ pitch and $0.02 \mathrm{~mm}$ depth and of $1.5 \mathrm{~mm}$ pitch and $0.05 \mathrm{~mm}$ depth, as shown in Fig. 20 on the test engine. Fig. 21 shows the results. In the case of $0.05 \mathrm{~mm}$-deep finish, the wear was normal for 48 hours while the tool mark remained and once the tool mark vanished, abnormal wear set in. In the case of $0.02 \mathrm{~mm}$-deep finish, the tool mark vanished in 23 hours of operation, and the wear had the same tendency. This indicates that it is sufficient if the tool mark remains until the ring has completed the running-in and attains the shape favourable for the formation of viscous oil film. The influence of finishing by tool cutting, the wedge action or the oil holding effect due to the undulation of tool mark can also be thought of, but as seen in Fig. 22, the liner surface finished by tool cutting shows removal of compound of metal, forming microscopic oil pockets. These seem to aid the recovery of boundary oil film.

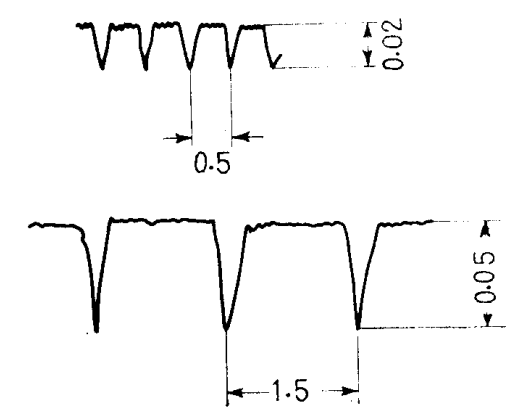

Fig. 20 Liner surfaces finished by tool cutting

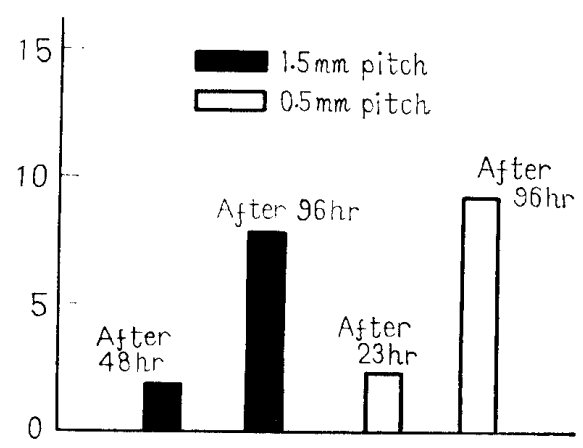

Fig. 21 Effect of finishing by tool cutting

\section{Conclusions}

1) In the lubrication of piston rings at the initial stage at high temperature and low speed, the major part of friction at the middle of stroke is composed of that of the boundary and solid contact part, but the load is carried mostly by the viscous oil film pressure. At both dead centers of stroke, however, the rings are subjected to a severe condition of 0.15 to 0.20 of frictional coefficient due to edge loading.

2) As the edges of piston rings are rounded off naturally by edge loading, the frictional coefficient at both ends of stroke declines in comparatively short time and the lubrication condition turns better. However, if the rings are forced in that stage, scuffing would occur and abnormal wear would result from the hard abrasive scraped off from the base metal.

3) Once abnormal wear sets in, the middle part of the ring is scraped and the sliding surface is not rounded off. Consequently, the lubrication condition does not turn better and abnormal wear continues for a long time.

4) The high alkaline cylinder oil lacks in thermal stability and deposits hard sludge which obstructs the formation of lubricating oil film as soft abrasive, causing scuffing. Therefore, it is not advisable to use this type of oil at the runningin stage.

5) The cylinder liner of FC system is not liable to cause abnormal wear, but has a high wear rate of the liner itself. The liner of $\mathrm{P}$ system is excellent both against abnormal wear and the wear of the liner itself, and the liner of $\mathrm{H} \cdot \mathrm{P}$ system is especially good. The liner of $\mathrm{P}-\mathrm{V}$ system with a trace of vanadium showed the best results, but the $\mathrm{V}$-content is important because too much vanadium added expedites abnormal wear.

6) The chamfered ring with sliding surface

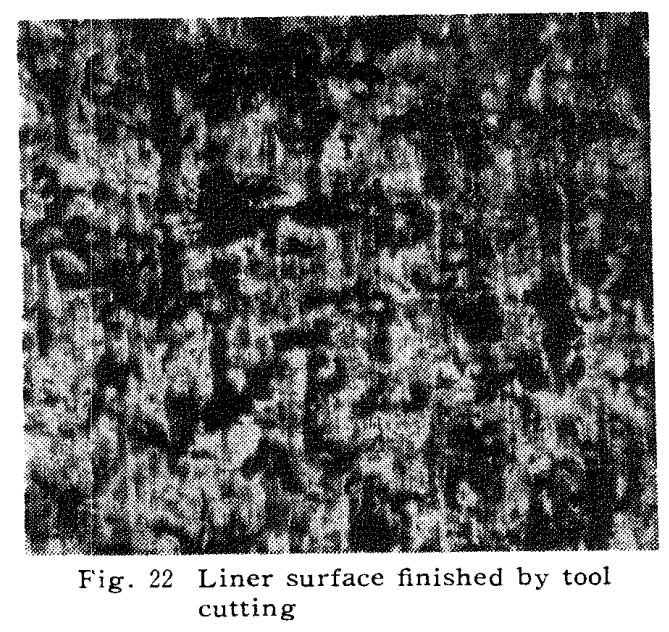


slightly rounded off is effective for the prevention of abnormal wear, because the edge loading at both dead centers of stroke is prevented.

7) Finishing of the liner surface by tool cutting is an effective measure for the prevention of abnormal wear.

\section{Acknowledgements}

The authors express their sincerest gratitude to Prof. N. Soda of Tokyo University and Prof. F. Hirano of Kyushu University who gave unsparing guidance in this study, to Prof. S. Furuhama of Musashi Institute of Technology for his valuable advices on the test equipment, and to the Research Department of Mitsubishi Petroleum Co., Nippon Piston Ring Co., Riken Piston Ring Co., and Teikoku Piston Ring Co. for their cooperation.

\section{References}

(1) Y. Wakuri and K. Katsuta: Jour. Japan Soc. Lub. Engrs., Vol. 5, No. 6 (1960), p. 342.

(2) S. Furuhama: Trans. Japan Sor. Mech. Engrs., Vol. 25, No. 158 (1959), p.1034.

(3) M. Soda: Masatsu to Junkatsu, (1959), p. 90, Iwanami Shoten.

(4) S. Furuhama: Jour. Japan Soc. Lub. Engrs., Vol. 7, No. 3 (1962) p. 105.

(5) F. Hirano: Science of Machine, Vol. 11, No. (1959), p. 16. (Japan)

\section{Discussion}

J. Akнока: (1) The frictional force is larger at the dead points than at the mid-way of the piston-stroke as in Fig. 11. The larger frictional force suggests the poorer lublication and consequently the larger wear, so the weared surface must be rounded at the dead points due to wear by edge-loading. But the flat weared surface in Fig. 13 shows that considerable wear occurs at all points of the piston-stroke as a typical wear by abrasion and the wear at the dead points is not so significant. How is the wear-rate at the mid-way and at the dead points ?

(2) How are the effects of fuel?

(3) How are the effects of generation of oxide-film?

(4) How are the wear-particles? The wearparticles may be quite important to prove the mechanism of wear.

(5) Does the deterioration property of lubricants by temperature in the experimental devices coincide with that of the physical and chemical tests?

(6) How are the effects of quantity of lubricants?

S. Furuhama: (7) It would be very important for the study on the wear and lubrication of an internal combustion engine that the operating conditions be made as similar as possible between the model and a real thing.

More specifically speaking: (i ) In a real engine the value of $\mu U / W$ will amount to about 10 times the value in a model, and the lubrication will assume approximately the characteristic of fluid lubrication, so except at top dead center, the load will be supported fully by the oil film.

(ii) Is it not possible that in the case of abnormal wear the ring surface fails to create an oil pressure and accordingly there is no sealing assured; as the result the back pressure of lower ring increases, causing abnormal wear, or imperfect sealing from the first causes abnormal wear?

(iii) In the case of Fig. 15, is the ring frictionforce under the operating conditions fluidable or non-fluidable?

(8) The discusser wishes that the authors explain how the high alkaline oil is harmful to the initial running-in. For example, what is the "chemical polishing"? What action is exerted on the frictional surface by what component of additives?

(9) In the authors' test, extremely worse conditions than real conditions are adopted because the $W / B$ value decrease with small $B$; accordingly, it would be very dangerous or even meaningless to apply the results of this test for the explanation of wear phenomenon. For this reason, the authors should make theoretical calculations for the oilfilm-thickness of the piston-ring anew with the above point taken into account.

(10) The term "edge loading" is often encountered in the test. Since it is not yet confirmed whether or not the actual mechanism of running-in takes place in the ring, as described by the authors, this term should be employed with more caution.

(11) The authors ignore the oil film thikness in their treatment of wear phenomenon. In that case, it would be entirely nonsence to try to obtain agreement in the value of $\mu \mathrm{U} / W$ or to make the present basic experiment itself.

(12) To assure agreement in $\mu U / W$, the prerequisite will be to have the same $B$ dimentions of ring, the same prolile of sliding surface and the same stroke of engine. From this standpoint, it seems that too much bothering with $\mu U / W$ has caused misunderstanding.

(13) Therefore, it may be impossible to assure 
the same oil film thickness over the entire stroke. How about agreement in TDC?

(14) To secure agreement in the geometrical dimentions of ring, it would be better to make the ring width as wear to that of a real thing as possible.

(15) Contrary to the principle of the authors' test, it would be more effective to adopt a wider ring and accelerate the rotation.

H. SAGARA: (16) Does Fig. 20 vary from actual shape of cuts finished by halebite? Shape is not good and cuts seem to be too deep compared with pitches. Is liner above or below line?

(17) Does a small ring of $3 \mathrm{~mm}$ in width wear more rapidly than wide ring used in large engine when same unit load is acted on surface?

\section{Authors' closure}

(1) The authors are of the opinion that the accelerating factor for abnormal wear is the wear caused by hard abrasive, as you point out, and stated to that effect in the paper. By the word "secondary" in the paper the authors do not mean "secondary" quantitatively, but mean the order in the mechanism of occurrence of abrasive wear following the scuffing which occurs first. From the features of the ring profile and the fact that the rate of wear is higher with the lower rings, the authors consider that the quantitative acceleration is caused by the abrasive wear. Of course, oneto-one correspondence of friction and rate of wear can be considered only in the special case of ideal normal wear, and the authors do not relate these directly. In Fig. 11, $\eta$ in the case of abnormal wear is high at both ends of stroke, but the authors do not mean to say that therefore the rate of wear is also high, but mean that the high $\eta$ means severer lubrication condition which is liable to cause scuffing. They put emphasis on the following point. In normal wear, both edges of the ring are worn by edge loading, while the center part is worn little and the ring surface is rounded, the lubrication condition taking a favourable turn in a short time. However, once abnormal wear sets in, the rate of wear of the ring is high due to large hard abrasives at the middle of stroke where the middle part of the ring slides, and the ring surface is not rounded and the lubrication condition does not take a favourable turn as time passes. This means not only that $\eta$ at both dead centers of stroke remains high but also that $\eta$ at the middle of stroke is high. By introducing the friction characteristics in the paper, the authors do not intend to connect friction with the rate of wear, but mean to explain the difference in the mechanism of abnormal wear and normal wear. However, the relative weight of the rate of wear at both dead centers and that at the middle of stroke is yet to be clarified.

(2) There is a theory that as very little cylinder oil is fed to large diesel engines with lubricator oil feed, the lubrication is effected mainly by the fuel oil. In the experiences of abnormal wear with sea-faring vessels, however, the influences of cylinder oil and the liner materials are dominant, but the fuel oil, ranging from light oil in the present experiment to the cracked residual oil, does not show any significant difference. Therefore, the effect of fuel oil seems to be small, if any.

(3) The oxide film theory seems to maintain that the oxide film of oil aids the lubrication and in the case of high alkaline oil, the additive consumes acid and the formation of oxide film is hampered. This cannot be denied. However, in the test on the small test engine described in the paper, abnormal wear occurs with some liner materials even with fuel oil of $3 \%$ sulphur content and low alkaline cylinder oil, and it cannot be concluded that the oxide film acts as a controlling factor.

This means at the same time that the soft abrasive theory as stated in the paper is not an absolute one.

The authors advocate the soft abrasive theory based on the fact that the high alkaline oil lacks extremely in the extensivity (or recovery of boundary oil film) and deposits hard sludge at high temperature, but it is impossible to draw an absolute conclusion. Nevertheless, it can be maintained that the high alkaline oil is a dominant creative factor for abnormal wear.

(4) For the worn particles, the authors washed the rings subjected to abnormal wear and to normal wear together with the piston in $\mathrm{CCl}_{4}$, added straight oil of high viscosity and allowed for 24 hours to settle. Then they took the solids settled on the bottom of the beaker with a syringe together with the solvent and placed it on a slide glass. The solids are suspended in the solvent spread on the slide glass. The particles were observed under a microscope, when a ring magnet placed under the slide glass caused the particles containing $\mathrm{Fe}$ arranged by magnetism, which helped to discern worn particles from sludge. In the case of normal wear, particle sizes of from 0.1 to 0.2 microns were dominant, while in the case of abnormal wear, the particle sizes ranged from $2 \sim 3$ microns to $20 \sim 30$ microns, and there was a significant difference in particle size. However, these cannot readily be decided to be single particles, but they may be aggregations of particles in bridge, and further study in this respect is yet to be made. 
(5) For the judgement of the deterioration property of oil, the authors conducted the ordinary panel coking test, besides the oil film extensivity test as described in the paper. The results are not of the nature as coincides perfectly with the test results. The deposition of sludge in a limited time would not coincide with the fall in fluidity and deposition of sludge due to evaporation of volatile component in a long time as in the case of actual liners, and it seems to be the problem of adaptability of the test methods.

(6) The authors tested the feed rate of cylinder oil with many sea-faring vessels, but no significant influence was observed within the practical range of oil feed.

(7) As you pointed out, it is desirable that the law of similarity holds in principle between the model test and a real thing, and in the case of the present research the ring number $\mu U / W$ value is thought to be the standard of similarity in a way. In the present research, as the subject of the study is a large-sized marine engine, the width of the sliding surface is several times as large, accordingly $W$ is several times as large and $U$ is also about 10 times as large as the test model, but $\mu U / W$ value is almost the same between them.

Squeeze film effect must be considered in the actual engines, and the test was done in the same degree of rotational speed as in the real engine.

The above law of similarity can be adapted to the complete viscous lubrication condition, therefore it is doubtful whether this law will be the necessary and sufficient foundation in the case of examining the phenomena under the conditions mixed with boundary or solid contact. For example, there might be considered the method of making the oil film thicknesses agree with each other, even if the geometrical and dynamical similarity is disregarded. As the prime purpose of the present experiment is to grasp the edge loading phenomena, etc. at both ends of the stroke, (dynamically and geometrically similar) $\mu U / W$ value was made the standard in order to make $h / B$ value agree between the model and the real thing. This is the same as the case in which Sommerfeld number and $\mu N / P$ value are made the standards in order to examine friction coefficient and seizure limit in bearing. The present method is not, however, thought to be sufficient in order to examine the complicated surface phenomena and further study is desirable.

The next consideration is on the load carrying capacity ratio as you pointed out in (i). As for a high speed engine, not only the $\mu U / W$ value is larger, but also the friction coefficient is lower because of the fact that lubrication becomes easier at both the ends and the middle point of the stroke due to squeeze effect. On the contrary, for a low speed large engine, $100 \%$ viscous load carrying capacity is unthinkable. It is, of course, possible that most of the load is sustained by viscous oil film, but it may not always be said that resistance is for the most part viscous friction.

Regarding your question in (ii), if such a thing as you said happened, it would, of course, be the cause of abnormal wear. Such a thing would not, however, be thought a dominant cause, judging from the unified results of the effects produced both by cylinder oil used in running-in and by liner material, shown in Table 1 . If such a thing as you pointed out was dominant, the data would fluctuate and not be unified.

Next, as for (iii), it goes without saying that frictional characteristics are justly not fluidable locally under the developing condition of wear, but the friction-force of the engine in the experiment was not measured, so that it is impossible to judge the frictional characteristics on the whole ring.

(8) Because high alkaline cylinder oil is mixed with a large quantity of alkaline additives (mainly metalic calcium), its extensivity of oil film at high temperature is extremely bad as is shown in Fig. 12, repairability of boundary oil film is hampered, so that severe scuffing seems to be caused. Calcium salts, as the additives, deposit hard sludges (such as calcium oxide and calcium sulfate), and these become soft abrasives and hamper the formation of oil film in the same way as mentioned above. Once scuffing has begun, scrapings of metal compound become operative and accelerate wear in the form of a hard abrasive, as can be seen also from the high wear rate of lower rings and the ring profile.

Chemical polishing means here that sulfuric acid produces iron sulfate, the convex part easily peels off and lubrication is made easier, but in a wider meaning it improves frictional characteristics by virtue of producing a thin compound film over the metal surface by the action of the sulfur in the oil and the chlorine as an extreme additive, etc.

(9) In treating the abnormal wear phenomenon, whose mechanism is complicated and in which various unknown control factors are thought to exist, it is the usual method to make the focus as small as possible and to augment each effect as much as possible in the test, therefore the result of the test can't be called insignificant even if the condition in one part is severe. Of course it is desirable that the fixed condition, whose effective degree is unknown, is made to agree with the real thing. When it is impossible to make all of them 
agree, it will be unavoidable to disregard some of them in the test, won't it ? In the present research, 1) it is one of the trials to make the absolute value of the oil film thickness agree as you said, and 2) it is also one of the methods to make geometrical and dynamical similarity agree. [The fact, which you pointed out, that the $\mu U / W$ value makes no great difference from that of the real engine, has been already explained]. For example, the formation of the sliding surface profile in a) can't be explained without considering the edge loading of the ring, and profile is thought to depend on the gemetrical and dynamical similarity rather than the absolute value of the oil film thickness, so the authors chose the former as the standard. In this case, the difference of oil film thickness is unavoidable. On the contrary, to try to make the oil film thickness agree doesn't bring the condition in 2) into existence when the test is performed on a small sized testing machine, so the differences from actual engine in viscous and boundary contact condition following the inclination of the ring are unavoidable. So there are both strong point and weakness in each method. Therefore, it can not be decided at the present time that there is a grave mistake except in 1 ).

The detailed explanation is omitted here; how. ever, the severity of the lubrication condition is not simple enough to be decided only by the viscous oil film thickness and surface roughness.

$W$, in your next question, is made half of the difference of gas pressure acting on the upper side and lower side of the ring. This is thought to be caused by the insufficient explanation of the formula (1), because there is a pressure chamfer in the middle of the piston and rings are there at the upper and lower parts of the piston,

(the explanations of the sings are omitted)

$$
\begin{gathered}
W=2\left\{A \frac{P-P_{1}}{2}+A \frac{P_{1}-P_{2}}{2}\right. \\
\left.+\cdots \cdots A \frac{P_{n-1}-P_{n}}{2}\right\}+A_{n} P_{e} \\
P_{n}=0 \quad \therefore \quad W=A P+A_{n} P_{e}
\end{gathered}
$$

(10) Edge loading was reckoned according to the rounded ring after running in, which had been smooth at first, and frictional characteristics, etc., yet it is an unsettled fact.

(11) to (15) Though the following answer to your question won't be better than the former one, the author will try to answer it once again, considering the insufficiency of the former answer. The author doesn't think to have to make every experimental condition agree with the actual engine, as the prime purpose of this research is mainly aimed at the qualitative study of the mechanism of abnormal wear. It was, however, thought to be desirable to make the rotational speed, $\mu U / W$ value, the ratio between the ring size, and the roughness of the liner surfaces agree with each other, in order to make the conditions of the geometrical and dynamical similarity coincide with them. It was, however, a little difficult to make the ratio between the ring measures and the roughness of the liner surfaces agree, and the size of liner construction could't be decided; therefore the author decided to make $\mu U / W$ value the standard in a way. (It was said to be of course incomplete, even if we said we had made them agree, as there wasn't even a fluctua. tion of gas pressure).

To explain this idea more in detail, if the dynamical similarity conditions were made to meet, the distribution of oil film pressure acting on the ring and the twisting with inclination considered would be similar. If the model wear was supposed as a normal wear, the formation of the ring profile would be made similar in a way, and severity of scuffing could with good reason be based on these ideas.

Against these ideas, your theory seemed to suggest that it would be better to make the thickness of oil film agree in a way, by means of enlarging the ring measure and increasing the rotational speed. (Increasing the viscosity of oil film and decreasing the gas pressure were thought to be included). As it seems that your suggestion may be better, the authors desire to make further research. The basic test, however, would not be thought meaningless, only because the thickness of oil film did not agree. This results from the difference of opinion and it can't be helped.

(16) As you question, the actual shape of the liner surface differs from Fig. 20. Fig. 20 shows merely the depth and pitch of the tool mark as measured by the contact needle method.

(17) Because of differences of lubrication conditions, the authors do not maintain that the present results agree quantitatively with the results obtained with large engines. The tool marks disappeared in 48 hours and 23 hours in the present tests, but with actual large engines, the wear of tool marks after one year-operation is of an order of slight wear of the tips of tool marks and no abnormal wear occurred, finishing by tool cutting proving very effective. The present study aims at the qualitative clarification of the mechanism of abnormal wear, and the test conditions are somewhat different from the actual conditions. The authors, however, mean to emphasize the effectiveness of finishing by tool cutting. 